\title{
Are Our Hands Still Clean?
}

\author{
Ankur Bajaj $^{1} \odot$, Neha Chaurasiya ${ }^{2}$, Manjul Tripathi ${ }^{3}$
}

\section{Abstract}

"Clean Hands Save Lives," we have heard it numerous times. But are our hands really clean? We realized that the most neglected parts of our hands are the most medial part of the little finger and palm and the most lateral part of the index finger and palm. Putting an emphasis on it, we put forward two additional steps in the routine handwashing technique increasing to 9 steps instead of the previous 7 .

Keywords: COVID-19; Hand hygiene; Infection control.

Indian Journal of Critical Care Medicine (2021): 10.5005/jp-journals-10071-23824

Sir

In the times of COVID-19 crisis, the value of hand hygiene among healthcare workers is not merely a personal issue. ${ }^{1}$ According to United States Centers for Disease Control and Prevention (CDC), each year two million Americans acquire an infection while they are in the hospital. The hardest part of the infection control team in those hospitals is not coping with the variety of contagions they encounter or the panic that sometimes occurs among patients and staff. ${ }^{2}$ Instead, their greatest difficulty is getting clinicians to do one simple thing that consistently halts the spread of infection: washing their hands. ${ }^{3}$ There is not much, which has not been tried earlier.

"Clean Hands Save Lives," we have heard it numerous times. But are our hands really clean? Is WHO 7 Steps procedure adequate for cleanliness of our hands? ${ }^{4,5}$ We have noticed that WHO protocol covers maximum areas of the palms except for the most medial part of the little finger and palm and the most lateral part of the index finger and palm in the anatomical position. These areas are left neglected from scrubbing during the routine steps of surgical scrub and maybe a potential site of germ habitation. Putting an emphasis on it, we put forward two additional steps in the routine handwashing technique increasing to 9 steps instead of previous 7 (Fig. 1). These additional steps
${ }^{1}$ Department of Neurosurgery, King George's Medical University, Lucknow, Uttar Pradesh, India

${ }^{2}$ Department of Pathology, Balarampur Hospital, Lucknow, Uttar Pradesh, India

${ }^{3}$ Department of Neurosurgery, PostGraduate Institute of Medical Science, Chandīgarh, India

Corresponding Author: Manjul Tripathi, Department of Neurosurgery, PostGraduate Institute of Medical Science, Chandīgarh, India, e-mail: drmanjultripathi@gmail.com

How to cite this article: Bajaj A, Chaurasiya N, Tripathi M. Are Our Hands Still Clean? Indian J Crit Care Med 2021;25(5):601-602.

Source of support: Nil

Conflict of interest: None

should cover the neglected part of our hand making it "Clean Hands." These steps add 15 seconds more to the routine WHO protocol. Just additional 15 seconds make your hands safer in terms of transmitting infection. At present, our observation is a proof of concept which needs further validation with microbiological assessment in observational comparison with standard WHO protocol.

() Jaypee Brothers Medical Publishers. 2021 Open Access This article is distributed under the terms of the Creative Commons Attribution 4.0 International License (https://creativecommons.org/licenses/by-nc/4.0/), which permits unrestricted use, distribution, and non-commercial reproduction in any medium, provided you give appropriate credit to the original author(s) and the source, provide a link to the Creative Commons license, and indicate if changes were made. The Creative Commons Public Domain Dedication waiver (http://creativecommons.org/publicdomain/zero/1.0/) applies to the data made available in this article, unless otherwise stated. 


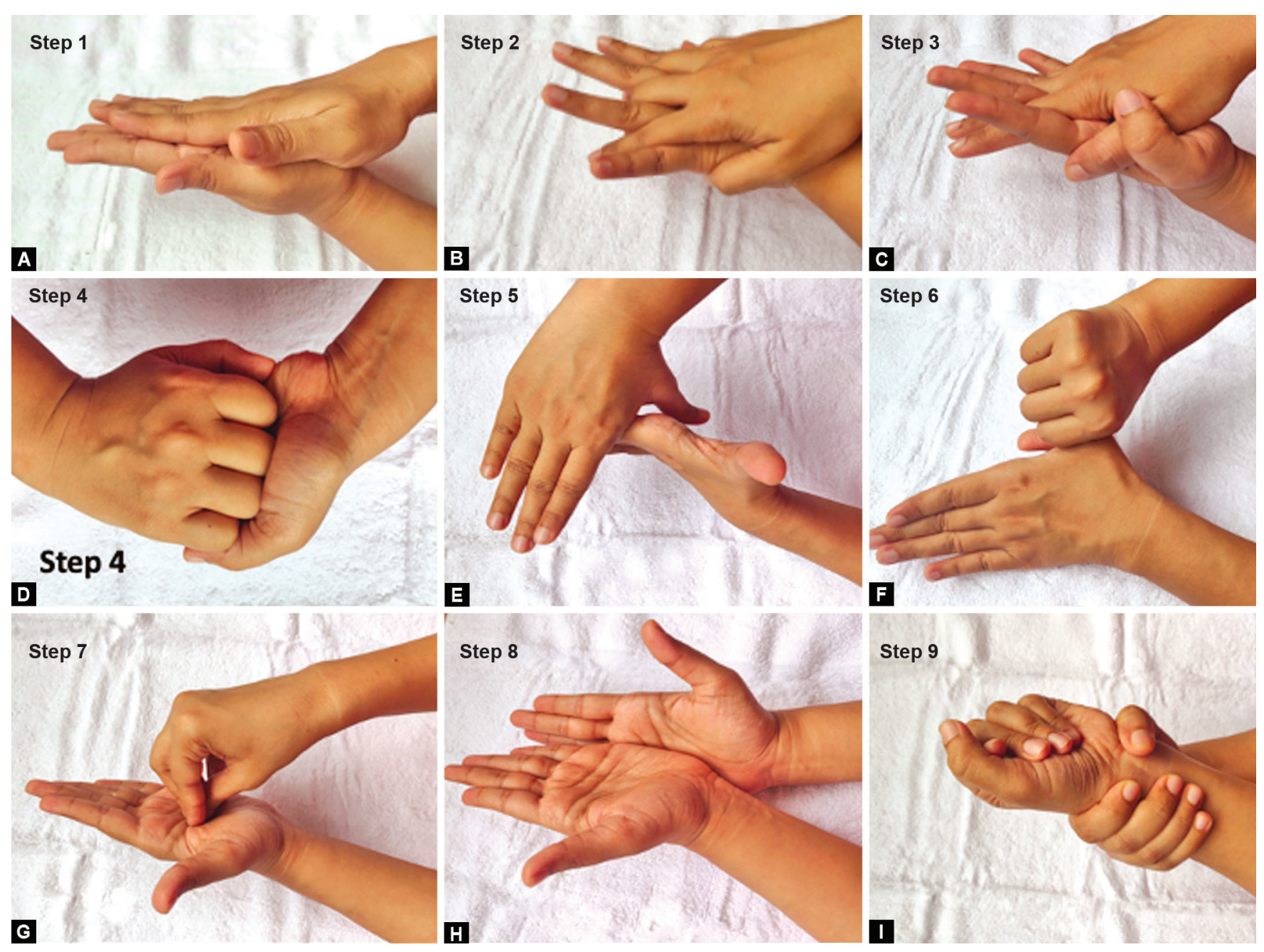

Figs $1 \mathrm{~A}$ to I: The proposed additions (steps 5 and 8 ) to the routine handwashing technique to cover the most medial and lateral aspect of the hand and the palm to the standard safe handwash practice

\section{ORCID}

Ankur Bajaj $\odot$ https://orcid.org/0000-0003-0243-4059

Neha Chaurasiya 나 https://orcid.org/0000-0001-5140-4169

Manjul Tripathi (1) https://orcid.org/0000-0002-5679-3439

\section{References}

1. Chavali S, Menon V, Shukla U. Hand hygiene compliance among healthcare workers in an accredited tertiary care hospital. Indian J Crit Care Med 2014;18(10):689-693. DOI: 10.4103/0972-5229.142179.
2. CDC definitions for nosocomial infections 2004. Atlanta, GA: Centers for Disease Control and Prevention; 2004.

3. WHO Guidelines on Hand Hygiene in Health Care. 2009. Available from: http://whqlibdoc.who.int/publications/2009/9789241597906_ eng.pdf.

4. George DA, Bhabra M. A guide to scrubbing in Student BMJ [Internet]; 2015. Available from: http://www.medscape.com/viewarticle/725336

5. Essential environmental health standards in health care. Geneva: World Health Organization; 2008. Available from: https://www.who. int/water_sanitation_health/publications/ehs_hc/en/[Accessed on: June 21, 2020]. 